\title{
Social Influence on Evacuation Behavior in Real and Virtual Environments
}

\author{
Max Kinateder* and William H. Warren \\ Department of Cognitive, Linguistic, and Psychological Sciences, Brown University, Providence, RI, USA
}

Virtual reality (VR) is a promising tool to study evacuation behavior as it allows experimentally controlled, safe simulation of otherwise dangerous situations. However, validation studies comparing evacuation behavior in real and virtual environments are still scarce. We compare the decision to evacuate in response to a fire alarm in matched physical and virtual environments. One hundred fifty participants were tested individually in a one-trial experiment in one of three conditions. In the Control condition, the fire alarm sounded while the participant performed a bogus perceptual matching task. In the Passive bystander condition, the participant performed the task together with a confederate who

OPEN ACCESS

Edited by: Massimo Bergamasco, Scuola Superiore Sant'Anna, Italy

Reviewed by: John Quarles, University of Texas at San Antonio, USA Benjamin Lok, University of Florida, USA

Victoria Interrante, University of Minnesota, USA

*Correspondence: Max Kinateder max_kinateder@brown.edu

Specialty section: This article was submitted to Virtual Environments, a section of the journal Frontiers in Robotics and Al

Received: 14 April 2016 Accepted: 01 July 2016 Published: 25 July 2016

Citation:

Kinateder M and Warren WH (2016) Social Influence on

Evacuation Behavior in Real and Virtual Environments.

Front. Robot. Al 3:43. doi: 10.3389/frobt.2016.00043 ignored the fire alarm. In the Active bystander condition, the confederate left the room when the fire alarm went off. Half of the participants in each condition experienced the scenario in the real laboratory and the other half in a matched virtual environment with a virtual bystander, presented in a head-mounted display. The active bystander group was more likely to evacuate and the passive bystander group less likely to evacuate than the control group. This pattern of social influence was observed in both the real and virtual environments, although the overall response to the virtual alarm was reduced; positive influence of bystanders was comparable, whereas negative influence was weaker in VR. We found no reliable gender effects for the participant or the bystander. These findings extend the social influence to the decision to evacuate, revealing a positive as well as the previous negative social influence. The results support the ecological validity of VR as a research tool to study evacuation behavior in emergency situations, with the caveat that effect sizes may be smaller in VR.

\section{Keywords: virtual reality, fire evacuation, social influence, bystander effect, virtual humans, virtual agents}

\section{INTRODUCTION}

The people around us influence our responses to emergency situations. As early as the 1960s, Latané and Darley (1968) demonstrated a social influence on fire evacuation behavior. In their seminal smoke-filled room study, participants waited in a room that gradually filled with smoke. A participant either waited alone, with two other naive participants, or with two confederates who ignored the smoke and stayed in the room. Seventy-five percent of the solitary participants reported the smoke, whereas only $38 \%$ of the participants who were with other participants and only $10 \%$ of the participants who were with confederates did so. The results established that the passive behavior of bystanders exerts a negative social influence on evacuation behavior. The work of Latané and Darley (1968) has been the basis for extensive research on helping behavior 
in emergency situations (Fischer et al., 2011). However, there are remarkably few controlled experiments on social influence during emergency evacuation.

The advent of high-resolution, mobile virtual reality (VR) technology makes possible a new wave of experimental research on evacuation behavior. VR allows researchers to immerse human participants in complex, dangerous situations that are difficult to simulate in the real world, with maximum experimental control, minimal risk, and a vivid experience of presence (Tarr and Warren, 2002; Cummings and Bailenson, 2015). In evacuation research, VR has been used to study emergency training (Kinateder et al., 2013; Ribeiro et al., 2013), pre-evacuation behavior (Kobes et al., 2010a,b; McConnell et al., 2010), and the impact of way-finding installations (Ronchi et al., 2015; Andrée et al., 2016). VR offers the opportunity to study risky scenarios in a safe environment with a degree of control and replicability that cannot be achieved in field studies (Kinateder et al., 2014b).

Several previous studies have used VR to investigate human behavior in emergency situations. Slater et al. (2013) demonstrated that virtual humans exert a social influence on the decision to intervene in a simulated violent incident in VR. Specifically, participants were more likely to verbally and physically intervene on behalf of a virtual human that appeared to be a member of their in-group than on behalf of one that did not. Similarly, during a virtual fire emergency, Gamberini et al. (2015) found that light-skinned participants were less likely to offer help to a darker-skinned virtual human compared to a lighter-skinned virtual human. Participants in this study also reported an increased state anxiety during the simulated fire emergency compared to a control condition. In an observational study on fire evacuation, Gamberini et al. (2003) tested responses to a simulated fire while exploring a virtual library; participants functionally adapted their behavior according to the fire emergency and switched from exploratory movement to egress behavior. More recently, VR was used to experimentally study social influence on evacuation behavior in a virtual road tunnel accident with smoke and fire. These experiments found that the behavior of virtual humans affected the decision to evacuate, exit choice, and egress route patterns during evacuation (Kinateder et al., 2012, 2014a,c). In particular, Kinateder et al. (2014a) showed that passive virtual humans led participants to delay evacuation decisions in a virtual tunnel fire.

Before VR can be adopted as a methodology for evacuation research, however, its external validity must be established. Yet, comparative experiments are still rare [see Kinateder et al. (2014b) for an overview]. One can ask broadly whether behavioral, cognitive, emotional, and psychophysiological responses in VR are comparable to those in similar situations in the real world. In the last two decades, studies have demonstrated the validity of driving simulators for driving behavior (Kaptein et al., 1996; Godley et al., 2002), the ability of virtual environments to elicit adequate emotional responses (Mühlberger et al., 2007), and the transfer of VR evacuation training to real-world behavior (Kobes et al., 2010a; Kinateder et al., 2013). If external validity can be established in basic scenarios, the promise of the technique is that VR might be leveraged to study situations that are too difficult or dangerous to create in the real environment.
Inspired by the smoke-filled room study of Latané and Darley (1968), the present experiment investigates social influence and gender effects on evacuation behavior in response to a fire alarm in both real and virtual environments. Our first goal was to extend the well-established social influence effect on the decision to evacuate during a fire emergency in the real environment, testing a positive as well as a negative social influence on the participant. Previous studies on social influence effects in emergency situations mostly focused on negative effects on helping behavior (Fischer et al., 2011). However, positive or negative effects of social influence on the decision to evacuate in the real world have not been experimentally tested earlier.

Our second goal was to compare the pattern of evacuation behavior in the real environment and a matched immersive virtual environment. The first validation study of evacuation behavior in desktop VR was performed by Kobes et al. (2010a). In their study, the influence of smoke and exit signs on wayfinding and evacuation behavior was tested in a real-world hotel and a virtual model of the hotel displayed on a computer monitor, through which participants navigated using a joystick. Although participants in both conditions were aware that they were taking part in an evacuation study, some of the real-world evacuation trials occurred at night, unannounced, while participants were sleeping in their hotel rooms, and several participants were tested at the same time. In the virtual counterpart, participants were tested individually during the daytime, with no virtual humans present, and the purpose of the experiment was disclosed prior to participation. Despite these methodological differences, the authors found several comparable behavioral patterns in the real and virtual tests. In both cases, the majority of participants went to the nearest emergency exit, but exit signs had a stronger effect on exit choice in the real environment, whereas smoke had a stronger effect on exit choice in the virtual environment.

The present experiment tested the influence of active and passive bystanders on evacuation decision-making and behavior in matched real and virtual environments. In a single-trial experiment, participants experienced an unannounced fire alarm either in the real laboratory room or in a virtual replica of the room. In the Control condition, the fire alarm sounded while the participant performed a bogus perceptual matching task. In the Passive bystander condition, the participant performed the task together with a confederate who ignored the fire alarm. In the Active bystander condition, the confederate left the room when the fire alarm went off. We aimed to minimize differences between the real and virtual versions of the experiment by using an immersive virtual environment, matched human confederates and virtual bystanders, and participants who were naive as to the purpose of the experiment.

\section{MATERIALS AND METHODS}

\section{Participants and Design}

One hundred fifty participants [74 female, $\mathrm{M}($ age $)=21.45$ years, $\mathrm{SD}=4.3$ ] completed the experiment. Another three volunteers were excluded due to technical or procedural errors. Informed consent was obtained from all volunteers, who were paid for their 
participation. Participants were randomly assigned to one of six experimental groups (25 per group), while attempting to balance for gender (Table 1). Half of the participants (40 female) were tested in the real environment and the other half (34 female) in the virtual environment, with no difference in mean age, $F(2,144)=0.70, p=0.50$. A third of the participants each were in the Active bystander, Passive bystander, and control conditions. This yielded a 2 (environment) $\times 3$ (bystander condition) between-subjects design. The study was approved by the Brown University institutional review board.

\section{Apparatus and Displays}

Testing was conducted in the Virtual Environment Navigation Lab (VENLab), a $14 \mathrm{~m} \times 16 \mathrm{~m}$ room. The entrance door to the lab was located on one side of the room. A standard fire alarm was mounted on the wall above the entrance door (SpectrAlert Advance P2R, System Sensor, St. Charles, IL, USA), which produced a siren sound and flashing strobe lights (similar models were present throughout the building). For the bogus task, a table with a laptop (Dell, Round Rock, TX, USA) and a flat-panel monitor were positioned about $3 \mathrm{~m}$ from the entrance door, near the center of the room. The participant stood $1 \mathrm{~m}$ in front of the table, facing the screen; in the bystander conditions, a male or female confederate stood next to the participant, between the participant and the door, also facing the screen. The participant could see the screen, confederate, and fire alarm from their position (Figure 1A).

In the real environment, the participant viewed the physical VENLab and a human confederate, while wearing a bicycle helmet with a head tracker affixed to it. In the virtual environment, the participant viewed a computer-generated replica of the VENLab in a wireless head-mounted display (HMD, Rift DK1, Oculus, Irvine, CA, USA) with a $110^{\circ}$ diagonal field of view (approximately $90^{\circ}$ horizontal and $65^{\circ}$ vertical) and a resolution of $640 \times 800$ pixels per eye. The participant's view of the real environment was occluded by a cloth hood. Displays were generated on a Dell XPS workstation (Round Rock, TX, USA) at a frame rate of $60 \mathrm{fps}$, using the Vizard 4 software package (WorldViz, Santa Monica, CA, USA) and transmitted to the HMD using a wireless HDMI transmitter (Nyrius, Niagara Falls, ON, Canada). Head position and orientation were recorded at a sampling rate of $60 \mathrm{~Hz}$ using a hybrid ultrasonic-inertial tracking system (IS-900, Intersense, Billerica, MA, USA), with a tracking area of $12 \mathrm{~m} \times 14 \mathrm{~m}$. Head coordinates from the tracker were used to update the display with a latency of 50-67 ms (3-4 frames).

The virtual environment consisted of a 3D computer graphics model of the laboratory room and a virtual doppelganger of a human confederate, created in 3Ds Max and Maya (Autodesk, San Rafael, CA, USA). A male and a female virtual human based on the two confederates were rendered using high-polygon $(\mathrm{M}=8099, \mathrm{SD}=813)$ and texture-mapped $(2048 \times 2048$ pixels $)$ $3 \mathrm{D}$ models, and animated at $60 \mathrm{fps}$. The virtual fire alarm and flashing light were simulated by a stereo directional sound source located above the virtual door, in the same position as the actual fire alarm; the virtual sound was a recording of the actual alarm (Figure 1B).

\section{Differences between Real and Virtual Environments}

Although the virtual version of the experiment aimed to be an exact replica of the real-world version, some differences could

TABLE 1 | Number of participants in each experimental group by gender.

\begin{tabular}{|c|c|c|c|c|c|c|c|}
\hline & \multicolumn{2}{|c|}{ Control condition } & \multicolumn{2}{|c|}{ Active bystander } & \multicolumn{2}{|c|}{ Passive bystander } & Total \\
\hline Female & 15 & 10 & 13 & 11 & 12 & 13 & 74 \\
\hline Age $[M(S D)]$ & $21.84(4.81)$ & $21.80(4.73)$ & $21.60(6.18)$ & $21.76(3.69)$ & 20.92 (3.3) & $20.80(2.55)$ & $21.45(4.30)$ \\
\hline
\end{tabular}
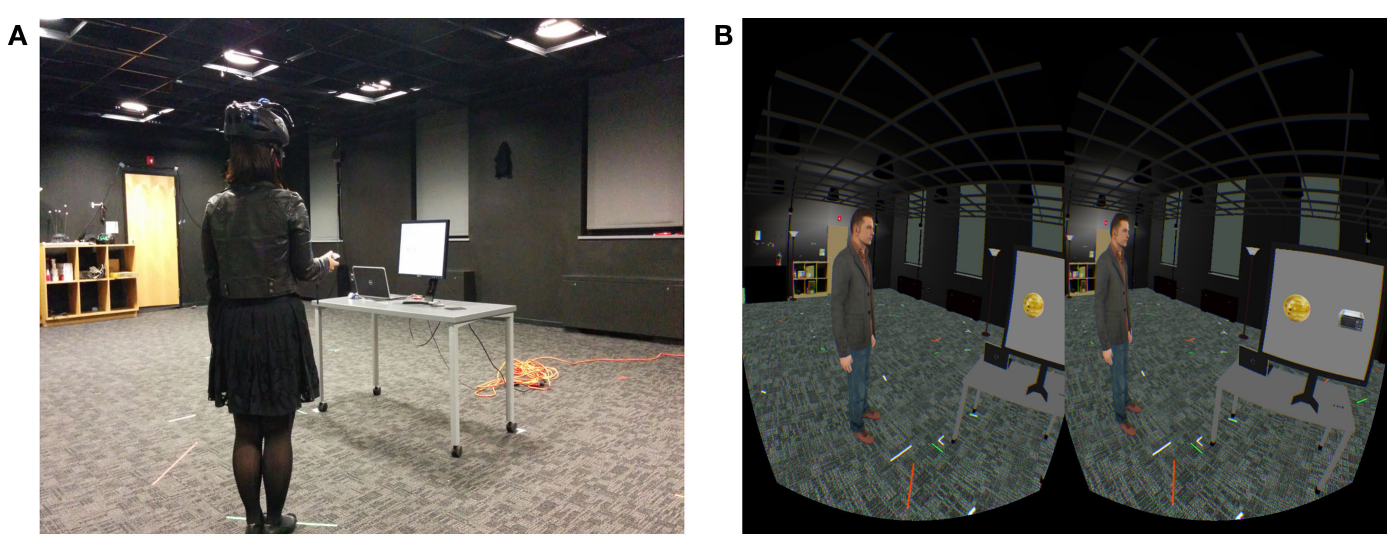

FIGURE 1 | (A) Participant in the real environment performing the bogus task in the control condition. The fire alarm over the entrance door in the background was activated during the experiment. (B) Stereo screenshot of the participant's view of the virtual environment in the passive bystander condition. 
not be avoided. First and foremost, participants were obviously aware that they were in VR. Second, for the bogus task, the pixel resolution of the HMD $(640 \times 800)$ was lower than that of the flatpanel monitor used to present the bogus stimuli $(1920 \times 1080)$. To insure that the stimuli were visible in the HMD, the size of the virtual monitor was increased to $150 \%$ of the size of the physical monitor. Third, in the real environment, the alarm sound was produced by a wall-mounted fire alarm, whereas in the virtual environment, the alarm sound was presented to participants over stereo headphones. Fourth, although the virtual humans closely resembled the real confederates, they were still clearly computergenerated figures and did not react to the participant's behavior. Fifth, in the real room, the experimenter read the instructions to the participants while standing behind the flat-panel monitor. In the virtual room, the instructions were prerecorded and played to participants through the headphones, while a virtual human stood in the location corresponding to that of the experimenter. Finally, in the real environment the participant could see their own body, whereas in the virtual environment they could not.

\section{Procedure}

Volunteers were recruited to participate in a study on "visual attention and head movement." Upon arrival at the lab, a cover story said that head movements would be monitored in order to "identify nodding movements while performing a visual attention task." In the bystander conditions, participants were told that another person (real or virtual) was present in order to "disentangle whether nodding was triggered through agreeing with another person or through understanding during a reasoning task." To explain the unresponsive behavior of the bystander in the virtual environment, participants in these groups were told that the virtual human was a recording of the previous participant and that their behavior would also be played back to the next participant. After giving consent, participants were led into the VENLab. For the real environment, participants and confederates (if present) put on the tracking helmets, were given handheld clickers for the bogus task, and were guided to their respective starting positions; for the virtual environment, participants put on the HMD and were instructed to explore the virtual environment and check that the virtual objects corresponded to physical objects (e.g., by touching the table and going to the door in the real room).

The experimenter (real and virtual) was standing behind the monitor and gave the same instructions for the bogus perceptual matching task to all participants. After reading the instructions, the experimenter walked out of the room and observed the experiment from behind a curtain. The participants stood in front of the table with flat-panel screen and were instructed to judge whether pairs of images matched by clicking a button on the handheld clicker. A pool of 99 images was generated from the POPORO data base which consists of images with norms for semantic relatedness (Kovalenko et al., 2012). Images from this pool were randomly presented in pairs for $2 \mathrm{~s}$ each. Participants received three blocks of 40 trials each. In each trial, participants had to decide whether images matched by color, shape, or content of the images or not at all. There was a $30 \mathrm{~s}$ break between each block.
Ten minutes into the bogus task (shortly after the beginning of the third block), the fire alarm sounded. In the Active bystander condition, the confederate (real or virtual) looked at the fire alarm and then turned, walked to the door, and exited. The confederate needed about $10 \mathrm{~s}$ to exit. In the Passive bystander condition, the confederate briefly looked at the alarm but continued performing the bogus task. The confederates in the real environment were instructed to respond as little as possible to the participants, and gave single word responses and did not engage in a conversation. If participants asked the confederates in the passive condition about what to do during the fire alarm, they were instructed to shrug and then return to the task (just as the virtual bystander did). The experiment ended after the participant either walked to the exit door or completed the third block of trials. The experimenter stopped participants as soon as they had reached the exit door.

Following testing, participants completed a questionnaire about the scenario and were fully debriefed. The questionnaire asked them to report whether they had recognized the fire alarm (yes/no), had thought that it was part of the experiment (yes/no), to rate its realism (four-point Likert scale from very unrealistic to very realistic), and to rate their perceived risk in the situation $(0-100$, with $0=$ no risk at all and $100=$ extreme risk). In addition, the virtual environment group received the iGroup Presence Questionnaire (IPQ) (Schubert, 2003), which included four sub-scales: spatial presence (degree of the sense of being physically present in VR), involvement (amount of attention focused on VR and the involvement experienced), experienced realism (subjective rating of realism of a virtual environment), and a single item general factor $(G)$ that correlates with all other factors. Each factor is reported on a scale from 0 (lowest) to 6 (highest).

\section{RESULTS}

Nearly, half of the 150 participants (73) walked to the exit, after the alarm sounded. Overall, more participants evacuated in the active bystander condition (38) and fewer in the passive bystander condition (9) compared to the control condition (26), confirming the social influence effect. This pattern was similar in the two environments (Figure 2), although fewer participants evacuated in the virtual environment (30) than in the real environment (43), overall. Figure 2 breaks down the absolute and relative frequencies of participants who decided to evacuate between the real and virtual environment and the three experimental conditions. The positive influence of the active bystander was comparable in the two environments, relative to the control condition, whereas the negative influence of the passive bystander was attenuated in VR.

The categorical choice data were analyzed using logistic regression (Table 2), based on a model in which the participant's evacuation decision (leave/stay) was predicted by bystander condition (active, passive, control) and environment (real, virtual). The reference category for the logistic regression model was the control condition in the real environment. The saturated model was required to explain the data adequately. For example, without the interaction term (bystander condition $\times$ environment) the model would be rejected, $p=0.017$. Since previous studies had found effect of gender on evacuation behavior 


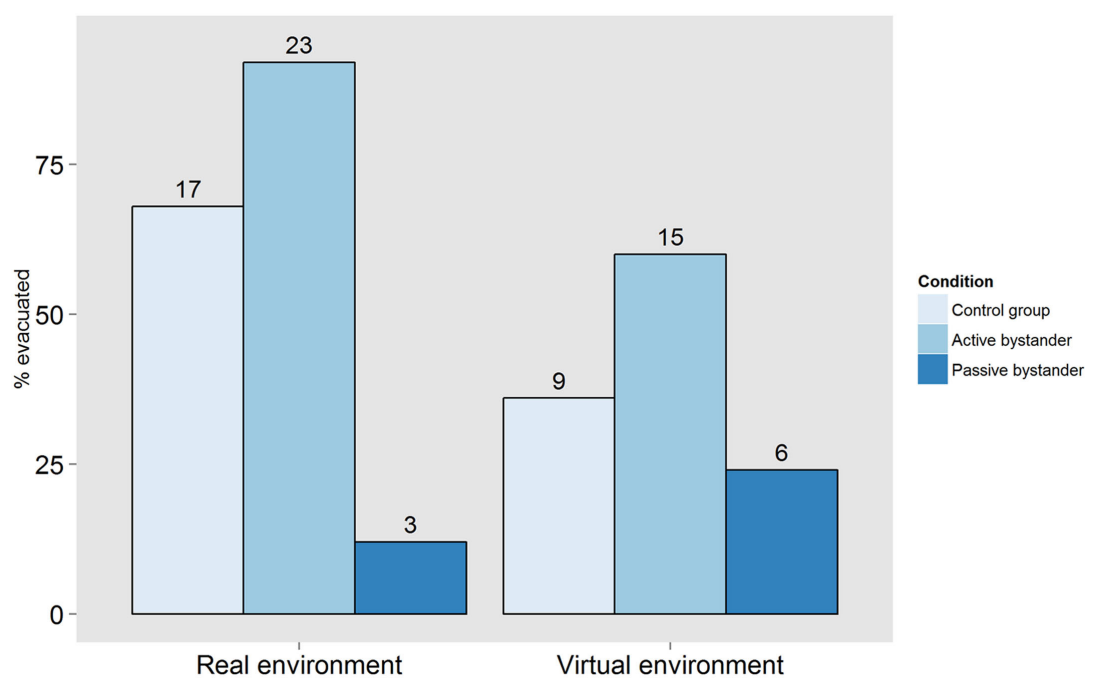

FIGURE 2 | Percentage of participants evacuating during the simulated fire alarm in each bystander condition (control group, active bystander, passive bystander) in virtual and real environment. The labels above each bar correspond to the absolute frequencies of evacuated participants.

TABLE 2 | Coefficients and confidence intervals for logistic regression predicting evacuation decision by experimental condition and world condition.

\begin{tabular}{|c|c|c|c|c|c|c|}
\hline & $b$ & $\operatorname{Exp}(b)=$ odds leaving & $1 / \exp (b)=$ odds staying & Lower $95 \% \mathrm{Cl}$ & Upper $95 \%$ Cl & $p$ \\
\hline Intercept & 0.75 & 2.12 & 0.47 & -0.06 & 1.65 & 0.08 \\
\hline \multicolumn{7}{|c|}{ Bystander condition } \\
\hline Active & 1.69 & 5.41 & 0.18 & 0.16 & 3.66 & $<0.05$ \\
\hline Passive & -2.75 & 0.06 & 15.58 & -4.39 & -1.39 & $<0.001$ \\
\hline Virtual environment & -1.33 & 0.26 & 3.78 & -2.55 & -0.19 & $<0.05$ \\
\hline \multicolumn{7}{|l|}{ Interaction } \\
\hline Active - VE & -0.71 & 0.49 & 2.03 & -2.94 & 1.23 & 0.49 \\
\hline Passive - VE & 2.17 & 8.75 & 0.11 & 0.30 & 4.19 & $<0.05$ \\
\hline
\end{tabular}

b, regression coefficient (logit odds); $\mathrm{Cl}$, confidence interval; VE, virtual environment.

$R^{2}=0.76$ (Hosmer-Lemeshow), 0.29 (Cox-Snell), 0.38 (Nagelkerke).

[e.g., Kinateder et al. (2013)], adding gender as a predictor, however, did not significantly improve the model, $p=0.19$.

All three predictor terms (bystander condition, environment, and interaction) significantly contributed to the model (Table 2). The main effect of bystander condition showed that participants were more likely to evacuate with an active bystander [odds (leaving) $=5.41$ ] and less likely to evacuate with a passive bystander [odds (staying) $=15.58$ ] compared to the control condition, after controlling for environment. The odds ratio (OR) of leaving was $($ active $/$ control $) /($ passive $/$ control $)=5.41 / 0.06=90.16$; that is, all else equal, the odds of evacuating in the active condition were ninety times those of evacuating in the passive condition. Similarly, the main effect of environment revealed that participants were less likely to evacuate the virtual room than the real room [odds (staying) $=3.78$ ] after controlling for bystander condition. There was a significant interaction between bystander condition and environment. Relative to the control condition, participants in the active condition responded similarly in the two environments [odds (leaving) $=0.49$ ], whereas participants in the passive condition were more likely to evacuate in the virtual environment than the real environment [odds (leaving) $=8.75$ ]
This indicates that the positive social influence was preserved but the negative social influence was significantly reduced in the virtual environment.

To further compare evacuation behavior in the real and virtual worlds, we analyzed the following variables for the 73 participants who evacuated: pre-movement time (between the fire alarm and the initiation of movement), movement time (between initiation of movement and arrival at the exit), mean walking speed and distance walked (during movement time, Table 3). The criterion for movement initiation was a head displacement $>0.5 \mathrm{~m}$ after the alarm was triggered. Shapiro-Wilk tests revealed that none of these four dependent variables were normally distributed (all $p<0.001)$ and, with the exception of distance, Bartlett tests of homoscedasticity indicated that variance across the bystander conditions was not homogeneous (all $p<0.01$ ). Consequently, Kruskal-Wallis rank sum tests were used to analyze effects of bystander condition and environment on the four variables. There were no effects of bystander condition or environment on pre-movement time, $\chi^{2}(2)=2.85, p=0.24$, movement time, $\chi^{2}(2)=5.28, p=0.07$, average walking speed, $\chi^{2}(2)=2.56$, $p=0.27$, and distance walked, $\chi^{2}(2)=0.20, p=0.90$. 
TABLE 3 | Pre-movement time, movement time, average walking speed, and total distance walked.

\begin{tabular}{|c|c|c|c|c|c|c|c|c|c|c|c|c|}
\hline & \multicolumn{4}{|c|}{ Control condition } & \multicolumn{4}{|c|}{ Active bystander } & \multicolumn{4}{|c|}{ Passive bystander } \\
\hline & \multicolumn{2}{|c|}{ Real } & \multicolumn{2}{|c|}{ Virtual } & \multicolumn{2}{|c|}{ Real } & \multicolumn{2}{|c|}{ Virtual } & \multicolumn{2}{|c|}{ Real } & \multicolumn{2}{|c|}{ Virtual } \\
\hline & $\mathbf{M}$ & SD & $\mathbf{M}$ & SD & $\mathbf{M}$ & SD & $\mathbf{M}$ & SD & $\mathbf{M}$ & SD & $\mathbf{M}$ & SD \\
\hline Pre-movement time & 26.10 & 19.30 & 15.73 & 10.20 & 20.59 & 5.88 & 30.81 & 44.64 & 22.80 & 15.75 & 16.47 & 11.01 \\
\hline Movement time & 5.33 & 1.99 & 10.77 & 10.15 & 5.37 & 1.80 & 12.37 & 18.47 & 8.14 & 0.97 & 6.73 & 1.88 \\
\hline Walking speed & 0.32 & 0.20 & 0.47 & 0.51 & 0.42 & 0.09 & 0.31 & 0.15 & 0.33 & 0.23 & 0.34 & 0.19 \\
\hline Distance & 6.96 & 1.22 & 6.91 & 1.74 & 6.31 & 0.73 & 7.75 & 2.61 & 8.32 & 1.79 & 6.30 & 0.63 \\
\hline
\end{tabular}

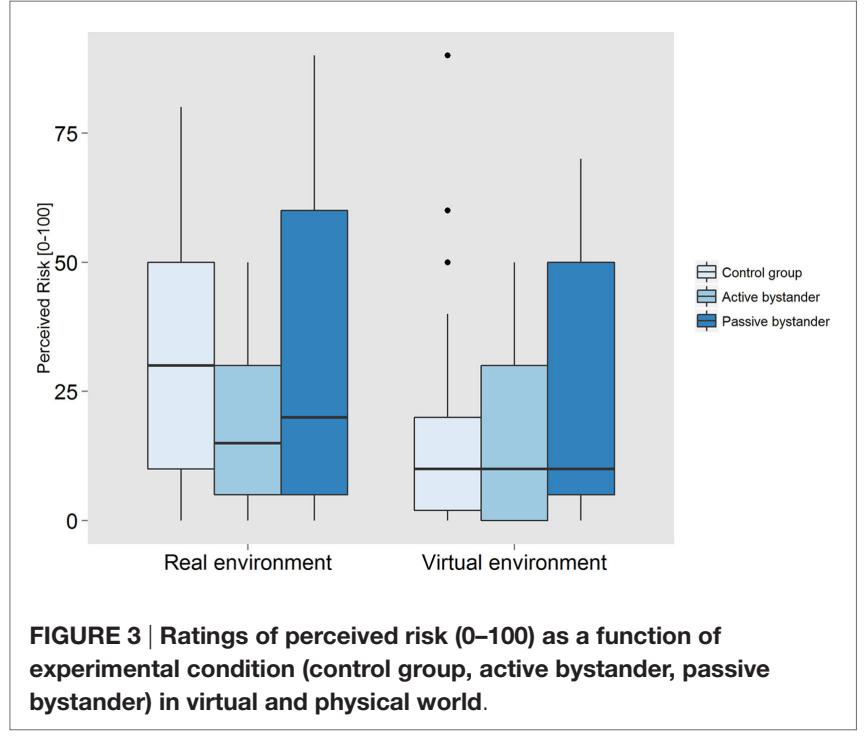

In the post-experiment questionnaire, participants reported higher perceived risk during the fire alarm in the real environment compared to the virtual environment, $F(1,144)=6.60, p<0.05$. There was no effect of bystander condition, $F(2,144)=2.56$, $p=0.08$, and no interaction, $F(2,144)=0.65, p=0.52$ (Figure 3 ), on perceived risk. Adding perceived risk to the logistic regression model did not significantly improve the predicted evacuation decision, $p=0.22$. In addition, $90 \%$ of the participants ( $88 \%$ in the real environment and $92 \%$ in the virtual environment) rated the simulated fire alarm as either "realistic" or "very realistic" and $87 \%$ recognized the simulated alarm as a fire alarm $(91 \%$ in the real environment and $84 \%$ in the virtual environment). However, only $20 \%$ in the real environment but $68 \%$ in the virtual environment reported that they thought the simulated fire alarm was part of the experiment.

In the IPQ, participants (virtual environment only) reported similar presence ratings in all conditions, with one exception. Experienced realism was reported to be significantly higher in the active bystander condition than in the control condition, $p<0.05$ (Table 4), consonant with the positive influence of the active virtual bystander.

\section{DISCUSSION}

The present study replicated and extended the social influence effect of the smoke-filled room study by Latané and Darley
TABLE 4 | iGroup Presence Questionnaire (IPQ) ratings.

\begin{tabular}{|c|c|c|c|c|c|c|c|c|}
\hline & \multicolumn{2}{|c|}{$\begin{array}{l}\text { Control } \\
\text { group }\end{array}$} & \multicolumn{2}{|c|}{$\begin{array}{l}\text { Passive } \\
\text { bystander }\end{array}$} & \multicolumn{2}{|c|}{$\begin{array}{c}\text { Active } \\
\text { bystander }\end{array}$} & \multirow[t]{2}{*}{$F$} & \multirow[t]{2}{*}{$p$} \\
\hline & $\mathbf{M}$ & SD & $\mathbf{M}$ & SD & $\mathbf{M}$ & SD & & \\
\hline $\mathrm{IPQ} G 1^{\mathrm{a}}$ & 4.20 & 1.41 & 3.96 & 1.77 & 4.68 & 0.85 & 1.72 & 0.19 \\
\hline $\begin{array}{l}\text { IPQ spatial } \\
\text { presence }^{a}\end{array}$ & 3.92 & 1.03 & 4.12 & 1.01 & 4.53 & 1.05 & 2.26 & 0.11 \\
\hline IPQ involvement ${ }^{a}$ & 3.15 & 1.30 & 3.12 & 1.09 & 3.58 & 1.00 & 1.28 & 0.28 \\
\hline $\begin{array}{l}\text { IPQ experienced } \\
\text { realism }^{\mathrm{a}}\end{array}$ & 2.28 & 1.01 & 2.71 & 1.00 & 2.96 & 0.86 & 3.23 & $<0.05$ \\
\hline
\end{tabular}

${ }^{a} n=75$ (virtual VENLab only); $n$ (Control group) $=25, n$ (Active bystander) $=25$, $n$ (Passive bystander) $=25$.

$I P Q$, iGroup Presence Questionnaire.

(1968), in matched real and virtual environments. First, we showed that the behavior of a bystander influences the decision to evacuate in response to a fire alarm in the real world. Participants were less likely to evacuate when a passive bystander was present during the alarm than when the participants were alone. Second, we found that bystanders exert a positive as well as a negative social influence, for participants were more likely to evacuate when the bystander did so. This discovery has the important implication that active bystanders can increase evacuation rates in emergency situations. Third, we replicated these social influence effects in a virtual environment. The pattern of evacuation responses was similar in the real and virtual environments. However, fewer participants overall chose to evacuate in response to the virtual fire alarm. The positive influence of the active bystander was comparable in the two environments, whereas the negative influence of the passive bystander was weaker in VR.

These results are consistent with recent studies demonstrating social influence on evacuation behavior in VR [e.g., Kinateder et al. (2014a)]. Previous experiments observed social influence effects of virtual humans, but did not compare matched virtual and real conditions (Kozlov and Johansen, 2010). Our findings are complementary to studies showing that participants react to violence in VR at the subjective and behavioral levels as if it were real (Slater et al., 2013). Although these studies had previously indicated that virtual humans can substitute for real humans when studying social situations, the present experiment is the first to systematically compare and quantify social influence in matched virtual and real environments.

Thus far, research on the social influence effect mostly focused on negative consequences of bystander behavior. The present 
study shows that bystanders can increase evacuation rates. Consequently, interventions that improve self-evacuation are likely to have a positive effect not only on the trained persons but also on their nearby neighbors. Future research should investigate the social influence of, for example, individuals who received evacuation training on nearby others in emergency situations.

Taken together, the present findings provide the best evidence, to date, that VR offers a valid tool for the study of evacuation behavior, with the caveat that effect sizes in VR may be smaller than those in the real world. Thus far, the vast majority of empirical evidence on evacuation behavior stems from uncontrolled observational studies. Laboratory experiments, which enable researchers to test causal relationships, have been underrepresented and criticized regarding their ecological validity. Although further validation studies are necessary, the present findings together with the advantages of VR open new avenues for controlled experiments in evacuation research. For example, more realistic emergency scenarios, including smoke and flames, could be tested with high experimental control in a safe environment. More prosaically, the present data allow better estimates of the required sample sizes for future VR experiments.

Observations from real emergencies and field studies suggest that the building occupants' gender affects evacuation behavior. For example, studies of hurricane evacuation demonstrated that women are more likely to evacuate than men (Bateman and Edwards, 2002; Enarson et al., 2007) and more likely to initiate a fire alarm and evacuate in tunnel emergencies (Kinateder et al., 2013). However, we observed no difference between the influence of the male and female bystander or between the responses of male and female participants. These results suggest that men and women exert a comparable social influence on the evacuation decisions of others, at least in dyadic interactions. Some caution is advisable in drawing implications from this null result. Because we used only one male and one female bystander in both the real and virtual environments, it is possible that any effects of gender were confounded with effects of other bystander characteristics. Future studies looking into gender effects should test multiple male and female bystanders and need to balance male and female participants more evenly across conditions with a larger sample size.

Self-reported perceived risk during the fire alarm was higher in the real than in the virtual environment. However, it did not predict the decision to evacuate in our study. The influence of perceived risk on evacuation decision-making is still not sufficiently understood (Kinateder et al., 2015); some studies find seemingly contradictory results, sometimes even on the same event (Kuligowski and Mileti, 2009; Day et al., 2013). Future research is clearly necessary to investigate if and how perceived risk influences evacuation decision-making and how it is linked to social influence.

Participants rated the virtual- and the physical-simulated fire alarm as equally realistic, and in both conditions the fire alarm was judged to be very convincing. Nonetheless, most participants in the virtual environment believed that the alarm was part of the experiment, whereas a large majority in the physical environment did not. On the one hand, these ratings demonstrate the quality of the mock fire alarm in the real room. On the other hand, they suggest that participants are aware that everything that happens in a virtual environment is controlled by the experimenter. However, it was not the aim of the study to convince participants that the fire alarm was real. If they experienced a virtual alarm as real, the appropriate response was to rip off the HMD and leave the building, and, in fact, none of the participants did so. In contrast, if they experienced themselves and the alarm as being "present" together in the virtual environment, the appropriate response was to walk to the virtual exit. The fact that $40 \%$ of VR participants did so (compared to $57 \%$ in the real room) suggests that the scenario achieved some degree of presence [see Cummings and Bailenson (2015) for an overview of the concept of presence in VR research]. The operational question, however, is whether the pattern of evacuation behavior elicited in the virtual environment was comparable to that observed in the real environment, and qualitatively, this can be answered in the affirmative.

Some limitations of the present study need to be considered. First, although the virtual environment matched the physical room as closely as possible, they were not identical (see Materials and Methods), and this may partially account for the reduced evacuation response in VR. Second, the present scenario did not include fire or smoke, and consequently further validation studies are necessary for behavior in virtual smoke or fire. Third, participants in the VR condition were instructed that the virtual human was a recording of the previous participant and that their own behavior would be played back to the following participant. It is possible that this drove participants to attend more closely to their own behavior than to the bystander in the virtual environment. However, we deem it more likely that this gave participants an explanation as to why the virtual human did not interact with them, while at the same time indicating that the virtual human's behavior was based on real behavior and not computer generated.

In summary, the present study extended the social influence effect to the decision to evacuate and demonstrated a positive as well as negative social influence, implying that active bystanders can increase evacuation rates. Moreover, this social influence on evacuation behavior was replicated in matched real and virtual environments for the first time. This result underscores the ecological validity of VR as a research tool for the experimental study of evacuation behavior in emergency situations, with the caveat that effect sizes may be reduced in VR.

\section{AUTHOR CONTRIBUTIONS}

MK and WW conceptualized the study, planned the experiment, interpreted the data, and wrote and revised the manuscript. MK collected and analyzed the data.

\section{ACKNOWLEDGMENTS}

The authors would like to thank Sara Palasits and Jason Roth for their help with the data collection and for acting as the two bystanders in the physical VENLab study.

\section{FUNDING}

The study was supported by the German Academic Exchange Service (DAAD). 


\section{REFERENCES}

Andrée, K., Nilsson, D., and Eriksson, J. (2016). Evacuation experiments in a virtual reality high-rise building: exit choice and waiting time for evacuation elevators. Fire Mater. 40, 554-567. doi:10.1002/fam.2310

Bateman, J. M., and Edwards, B. (2002). Gender and evacuation: a closer look at why women are more likely to evacuate for hurricanes. Nat. Hazards Rev. 3, 107-117. doi:10.1061/(ASCE)1527-6988(2002)3:3(107)

Cummings, J.J., and Bailenson, J.N. (2016). How immersive is enough? A meta-analysis of the effect of immersive technology on user presence. Media Psychol. 19, 272-309. doi:10.1080/15213269.2015.1015740

Day, R. C., Hulse, L. M., and Galea, E. R. (2013). Response phase behaviours and response time predictors of the $9 / 11$ World Trade Center evacuation. Fire Technol. 49, 657-678. doi:10.1007/s10694-012-0282-9

Enarson, E., Fothergill, A., and Peek, L. (2007). "Gender and disaster: foundations and directions," in Handbook of Disaster Research, eds H. Rodriguez, E. L. Quarantelli, and R. Dynes (Springer), 130-146.

Fischer, P., Krueger, J. I., Greitemeyer, T., Vogrincic, C., Kastenmuller, A., Frey, D., et al. (2011). The bystander-effect: a meta-analytic review on bystander intervention in dangerous and non-dangerous emergencies. Psychol. Bull. 137, 517-537. doi:10.1037/a0023304

Gamberini, L., Chittaro, L., Spagnolli, A., and Carlesso, C. (2015). Psychological response to an emergency in virtual reality: effects of victim ethnicity and emergency type on helping behavior and navigation. Comput. Human Behav. 48, 104-113. doi:10.1016/j.chb.2015.01.040

Gamberini, L., Cottone, P., Spagnolli, A., Varotto, D., and Mantovani, G. (2003). Responding to a fire emergency in a virtual environment: different patterns of action for different situations. Ergonomics 46, 842-858. doi:10.1080/00140130 31000111266

Godley, S. T., Triggs, T. J., and Fildes, B. N. (2002). Driving simulator validation for speed research. Accid. Anal. Prev. 34, 589-600. doi:10.1016/ S0001-4575(01)00056-2

Kaptein, N., Theeuwes, J., and Van Der Horst, R. (1996). Driving simulator validity: some considerations. Transp. Res. Rec. J. Transp. Res. Board 1550, 30-36. doi:10.3141/1550-05

Kinateder, M., Müller, M., Jost, M., Mühlberger, A., and Pauli, P. (2014a). Social influence in a virtual tunnel fire-influence of conflicting information on evacuation behavior. Appl. Ergon. 45, 1649-1659. doi:10.1016/j.apergo.2014. 05.014

Kinateder, M., Nilsson, D., Kobes, M., Müller, M., Pauli, P., and Mühlberger, A. (2014b). "Virtual reality for fire evacuation research," in Federated Conference on Computer Science and Information Systems, eds M. Ganzha, L. Maciaszek, and M. Paprzycki (Polskie Towarzystwo Informatyczne), 319-327.

Kinateder, M., Ronchi, E., Gromer, D., Müller, M., Jost, M., Nehfischer, M., et al. (2014c). Social influence on route choice in a virtual reality tunnel fire. Transp. Res. Part F Traffic Psychol. Behav. 6, 116-125. doi:10.1016/j.trf.2014.06.003

Kinateder, M., Müller, M., Mühlberger, A., and Pauli, P. (2012). "Social influence in a virtual tunnel fire - influence of passive virtual bystanders," in $5^{\text {th }}$ International Symposium on Human Behaviour in Fire (Interscience Communications Ltd.), 506-516.

Kinateder, M., Pauli, P., Muller, M., Krieger, J., Heimbecher, F., Ronnau, I., et al. (2013). Human behaviour in severe tunnel accidents: effects of information and behavioural training. Transp. Res. Part F Traffic Psychol. Behav. 17, 20-32. doi:10.1016/j.trf.2012.09.001
Kinateder, M. T., Kuligowski, E. D., Reneke, P. A., and Peacock, R. D. (2015). Risk perception in fire evacuation behavior revisited: definitions, related concepts, and empirical evidence. Fire Sci. Rev. 4, 1-26. doi:10.1186/s40038-014-0005-z

Kobes, M., Helsloot, I., De Vries, B., and Post, J. (2010a). Exit choice, (pre-)movement time and (pre-)evacuation behaviour in hotel fire evacuation - behavioural analysis and validation of the use of serious gaming in experimental research. Procedia Eng. 3, 37-51. doi:10.1016/j.proeng.2010.07.006

Kobes, M., Helsloot, I., De Vries, B., Post, J. G., Oberije, N., and Groenewegen, K. (2010b). Way finding during fire evacuation; an analysis of unannounced fire drills in a hotel at night. Build. Environ. 45, 537-548. doi:10.1016/j. buildenv.2009.07.004

Kovalenko, L. Y., Chaumon, M., and Busch, N. A. (2012). A pool of pairs of related objects (POPORO) for investigating visual semantic integration: behavioral and electrophysiological validation. Brain Topogr. 25, 272-284. doi:10.1007/ s10548-011-0216-8

Kozlov, M. D., and Johansen, M. K. (2010). Real behavior in virtual environments: psychology experiments in a simple virtual-reality paradigm using video games. Cyberpsychol. Behav. Soc. Netw. 13, 711-714. doi:10.1089/cyber.2009.0310

Kuligowski, E. D., and Mileti, D. S. (2009). Modeling pre-evacuation delay by occupants in World Trade Center towers 1 and 2 on September 11, 2001. Fire Saf. J. 44, 487-496. doi:10.1016/j.firesaf.2008.10.001

Latané, B., and Darley, J. M. (1968). Group inhibition of bystander intervention in emergencies. J. Pers. Soc. Psychol. 10, 215-221. doi:10.1037/h0026570

McConnell, N. C., Boyce, K. E., Shields, J., Galea, E. R., Day, R. C., and Hulse, L. M. (2010). The UK 9/11 evacuation study: analysis of survivors' recognition and response phase in WTC1. Fire Saf. J. 45, 21-34. doi:10.1016/j.firesaf.2009.09.001

Mühlberger, A., Bülthoff, H. H., Wiedemann, G., and Pauli, P. (2007). Virtual reality for the psychophysiological assessment of phobic fear: responses during virtual tunnel driving. Psychol. Assess. 19, 340-346. doi:10.1037/1040-3590.19.3.340

Ribeiro, C., Pereira, J., and Borbinha, J. (2013). "Creating awareness of emergency departments healthcare values using a serious game," in Scaling Up Learning for Sustained Impact, eds D. Hernández-Leo, T. Ley, R. Klamma, and A. Harrer (Springer), 502-507.

Ronchi, E., Nilsson, D., Kojić, S., Eriksson, J., Lovreglio, R., Modig, H., et al. (2016). A virtual reality experiment on flashing lights at emergency exit portals for road tunnel evacuation. Fire Technol. 52, 623-647. doi:10.1007/s10694-015-0462-5

Schubert, T. W. (2003). The sense of presence in virtual environments. Zeitschrift für Medienpsychologie 15, 69-71. doi:10.1026//1617-6383.15.2.69

Slater, M., Rovira, A., Southern, R., Swapp, D., Zhang, J. J., Campbell, C., et al. (2013). Bystander responses to a violent incident in an immersive virtual environment. PLoS ONE 8:e52766. doi:10.1371/journal.pone.0052766

Tarr, M. J., and Warren, W. H. (2002). Virtual reality in behavioral neuroscience and beyond. Nat. Neurosci. 5(Suppl.), 1089-1092. doi:10.1038/nn948

Conflict of Interest Statement: The authors declare that the research was conducted in the absence of any commercial or financial relationships that could be construed as a potential conflict of interest.

Copyright $\odot 2016$ Kinateder and Warren. This is an open-access article distributed under the terms of the Creative Commons Attribution License (CC BY). The use, distribution or reproduction in other forums is permitted, provided the original author(s) or licensor are credited and that the original publication in this journal is cited, in accordance with accepted academic practice. No use, distribution or reproduction is permitted which does not comply with these terms. 